\title{
Response of the Growth and Yield of Sunflower Hybrids to Organic and Inorganic Fertilization
}

\author{
Ilias TRAVLOS ${ }^{1)}$, Dimitrios BILALIS ${ }^{1 *}$, Panayiota PAPASTYLIANOU ${ }^{11}$, \\ Demosthenis CHACHALIS ${ }^{2)}$, Ippokratis LYGIZOS $^{1)}$, Ioannis ANNOUSAKIS ${ }^{1)}$ \\ and Yolanda PAPATHEOHARI ${ }^{1)}$ \\ ${ }^{1)}$ Laboratory of Agronomy, Agricultural University of Athens, Greece. \\ ${ }^{2)}$ Benaki Phytopathological Institute, Greece. \\ ${ }^{*}$ Corresponding author, e-mail: bilalisdimitrios@yahoo.gr
}

Bulletin UASVM Horticulture 71(2) / 2014

Print ISSN 1843-5254, Electronic ISSN 1843-5394

DOI:10.15835/buasvmcn-hort:10416

\begin{abstract}
Sunflower (Helianthus annuus L.) is economically one of the most important annual crops in the world grown for edible oil and for bio-energy purposes. Due to the high cost and the environmental concern, fertilization is among the agronomic inputs that ought to be reconsidered and further studied. The objectives of the present study were to evaluate the growth and productivity of three sunflower hybrids under several fertilization regimes. The experiment was conducted in Agricultural University of Athens according to the split-split plot design (randomized complete block) with three replicates, three main plots (inorganic, organic and untreated) and three subplots (sunflower hybrids: Neoma, P64HE39, P64LL62). Several growth and yield parameters were measured. The results indicated that Neoma was the most productive hybrid and the one which reacted better in terms of its vegetative growth in the incorporation of the organic compost. Organic fertilization had a significantly positive effect on yield and seed number of P64HE39 and P64LL62. Conclusively, organic fertilization of sunflower hybrids can result to high yields and it can be suggested as a successful practice to sunflower growers as long as the interactions between fertilization regime and hybrid are going to be taken into account.
\end{abstract}

Keywords: Helianthus annuus, organic fertilization

Introduction. Sunflower (Helianthus annuus L.) is economically one of the most important annual crops in the world grown primarily for edible oil and bio-energy purposes (De la Vega and Hall, 2002). In general, it is considered as a crop which can be successfully grown in many regions, since it is adaptable to a wide range of environmental conditions (Beard and Geng, 1982). However, the selection of the best hybrid for each area is a factor of major importance for the crop success and productivity. Nutrients can be added to the soil through inorganic or organic fertilizers. Inorganic fertilisers have the main advantage of providing nutrients in crop quickly available, while their cost and risk to degrade the environment are among the main disadvantages, therefore they are often replaced by organic manures and composts (Bilalis et al., 2010).

Aims and objectives. The objectives of the present study were to evaluate the growth and productivity of three sunflower hybrids under several fertilization regimes (organic, inorganic and untreated).

Materials and methods. A field experiment was conducted in the experimental field of the Agricultural University of Athens ( $37^{\circ} 59^{\prime} 12^{\prime \prime} \mathrm{N}$, $23^{\circ} 42^{\prime}$ 96" E, 29 m altitude). Soil was a clay loam (CL), the physicochemical characteristics of which ( 0 - to $15-\mathrm{cm}$ depth increment) were clay $352 \mathrm{~g} / \mathrm{kg}$, silt $457 \mathrm{~g} / \mathrm{kg}$, sand $191 \mathrm{~g} / \mathrm{kg}$, pH $\left(1: 2 \mathrm{H}_{2} \mathrm{O}\right) 8.2,1.75$ $\mathrm{g} / \mathrm{kg}$ total nitrogen, a medium supply of available phosphorus (P-Olsen $0.034 \mathrm{~g} / \mathrm{kg}$ ) and a good supply of available potassium $(0.88 \mathrm{~g} / \mathrm{kg})$. EC was $2700 \mu$ mhos, $\mathrm{CaCO}_{3} 330 \mathrm{~g} / \mathrm{kg}$ and organic matter content $24.4 \mathrm{~g} / \mathrm{kg}$. Three sunflower hybrids, namely 'Neoma', 'P64HE39' and 'P64LL62' were planted on 2 May 2014, while incorporation of an organic and an inorganic fertilizer (7-4-7 and 11$15-15$, respectively) was conducted before sowing. Both fertilizers were incorporated into the soil in 

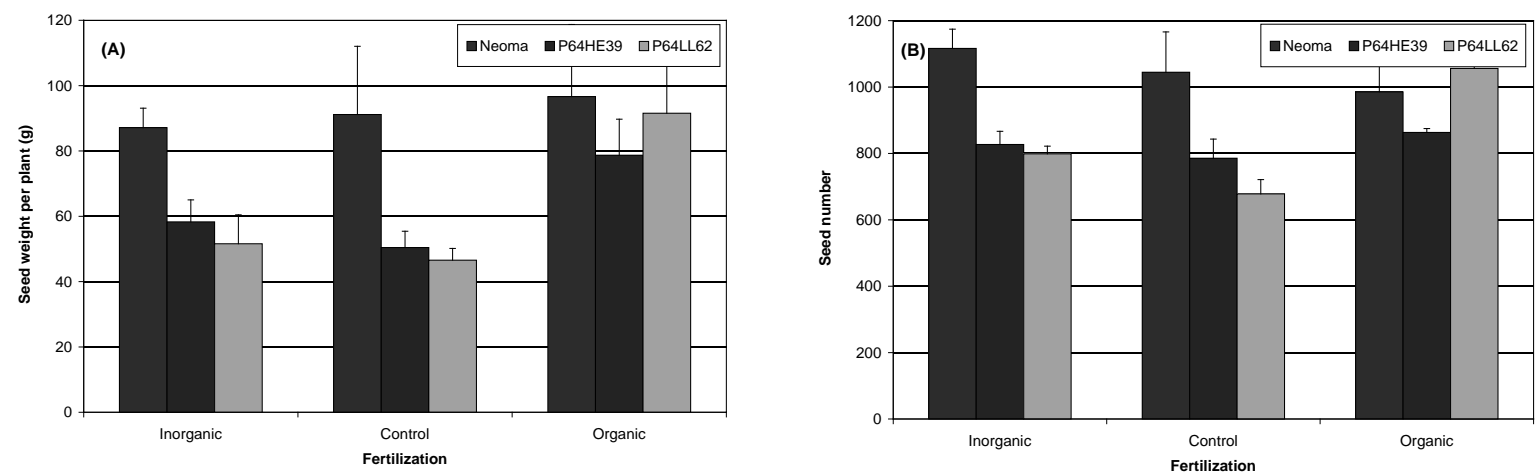

Fig. 1. A) Seed yield and B) seed number per plant for the three hybrids and the several fertilization regimes. Vertical bars denote standard errors of the means.

equivalent quantities. The experiment was set up on an area of $432 \mathrm{~m}^{2}$ according to the split-split plot design (randomized complete block) with three replicates, three main plots (inorganic, organic and untreated) and three subplots (sunflower hybrids). Five measurements on several growth parameters (plant height, number of leaves, leaf area, total biomass) were taken during the crop life cycle (at 42, 53, 61, 76 and 121 days after sowing, DAS). Leaf area was estimated by means of DT-area meter (Delta-T Devices Ltd, Burwell Cambridge, UK), while in harvest, grain yield was determined and measurements on seed number and dry weight of 1000 seeds were also taken.

Results and Discussion. The results of the present study indicated that the effects of fertilization on plant height and leaf area were significant, with the untreated plants being progressively and significantly less grown than the other plots. In particular, that was true for the hybrids Neoma and P64LL62.

Regarding seed yield, Neoma was the most productive hybrid. Organic fertilization had a significantly positive effect on grain yield and seed number of P64HE39 and P64LL62 (Fig.1). The effect of organic compost on the weight of 1000 seeds was also beneficial for all three hybrids.

Conclusion. In the present study, it was demonstrated that the organic fertilization of sunflower hybrids, even slow released, can result to high yields and it can be suggested as a successful practice to sunflower growers. In all cases, the interactions between fertilization regimes and hybrids should be taken into account.

\section{REFERENCES}

1. Beard BH, Geng S (1982). Interrelationships of morphological and economic characters of sunflower. Crop Sci 22:817-822.

2. Bilalis D, Karkanis A, Triantafyllidis V, Ladavos A, Patsiali S, Efthimiadou A, Papatheohari Y (2010). Effects of organic and inorganic fertilization on growth, yield and nicotine content of flue-cured and oriental tobacco (Nicotiana tabacum L.) seedlings grown in organic and conventional float system. J Food Agric Environ 8:585-589.

3. De la Vega AJ, Hall AJ (2002). Effects of planting date, genotype, and their interactions on sunflower yield: I. Determinants of oil-corrected grain yield. Crop Sci 42:1191-1201. 